\title{
The Study on Rural Vocational Education to Keep Within Limits of Poverty in the Era of Post Poverty
}

\author{
Hong Zeng \\ Sichuan University of Science \& Engineering \\ ZiGong, China \\ zh.jzm@qq.com
}

\author{
Xingzheng Xiao \\ Sichuan University of Science \& Engineering \\ ZiGong, China \\ 1714749418@qq.com
}

\begin{abstract}
The major purpose of this article is to discuss the farmer's vocational education and how to improve their technological consciousness through foster talents for the vocational education. Helping poor people to step into the Post Poverty and establish the pattern of sustainable affluence is so necessary. The method of solving the problem is to analyze the status of rural occupation first, then find out the existing problems in rural vocational education, and finally put forward some suggestions on the development of rural vocational education. Through the demonstration, it is concluded that only by increasing the training of rural workers' vocational education and supporting the development of rural vocational education can the peasants really get rid of poverty and stop the poverty and return to poverty. The innovation of this paper is to study rural vocational education from a new perspective. The key point is to curb farmers' poverty reduction in the era of post poverty alle viation.
\end{abstract}

Keywords-The era of Post Poverty; Vocational Education; keep within limits of poverty

\section{INTRODUCTION}

In order to change the state of the backward quality of famers, i t is necessary to develop the education and culture resources in rural areas. The fundamental policy of poverty alleviation is to build up a short board for the construction of cultural infrastructure and give full play to the role of culture in supporting the will and intelligence of the peasants. Since the implementation of targeted poverty alleviation, China has won the first battle in poverty alleviation and successfully step into the stage of overall poverty alleviation. To maintain the results of poverty alleviation and preventing the return to poverty in the post-poverty-free Era, we must help the farmer to set up aspiration and intelligence, strengthen the poverty alleviation of vocational education, promoting the development of Rural Vocational Education, improving the ability of poverty alleviation in Vocational Education, giving full play to the role of Vocational Education in tackling poverty alleviation, cutting off the intergenerational transmission of poverty, and establishing a sustainable poverty alleviation model.

\section{Analysis on the Current Situation of Poverty ALleViation in RuRAl Vocational EdUCATiOn}

\section{A. The situation of Rural Vocational Education in China}

According to the latest census data, China's current population is 13.8271 billion, of which 589.73 million are agricultural, accounting for $42.65 \%$ of the total population. In the total population of 80.42 million in Sichuan province, the poor compared with the 2000 census, in every one hundred thousand people with college culture degree of increased to 3611 from 8930, has a high school education from 11146 to 14032 people; The number of people with junior high school education rose from 33,961 to 38,788. The number of people with primary school education dropped from 35701 to 26779. The illiteracy rate was $4.08 \%$, down 2.64 percentage points from the $6.72 \%$ in the 2000 census. Although the scientific and cultural quality of our population has improved, there are obvious differences in the educational level of the urban and rural population. The crude illiteracy rate of the population is much higher than the level below $2 \%$ in developed countries. The gross enrolment ratio in universities is much lower than that in developed countries. The average number of years of education is not only lower than the average level of education in developed countries, but also lower than the world average level [1]. By the end of 2017, there are still 30.46 million people in our country who have not been lifted out of poverty, which is equivalent to the total population size of a mediumsized country. The poverty-stricken population is mainly concentrated in the relatively underdeveloped central and western regions. The poverty-stricken population of Guizhou, Yunnan, Henan, Guangxi, Hunan and Sichuan provinces is above 10 million.

\section{B. The main ways of povertyalleviation in China's rural areas at present}

According to Su Guoxia, director of the policy and regulation department of the Poverty Alleviation Office of the State Council, the development of educational undertakings in poor areas and the degree of education for children in poor families are obviously lags behind other regions. In the poverty-stricken filing family, more than half of the people have only primary school education degree. $22.3 \%$ of families said they could not get rid of poverty because of lack of skills[2]. China's rural poverty alleviation models are mainly in the following ways: 
One is the mode of financial poverty alleviation. The financial sector has a policy tilt towards poverty stricken areas through fiscal, tax preferences, special transfer payments, and the abolition of agricultural taxes, that vigorously support the development and construction of poor areas, which narrowing the gap between Poverty-stricken areas and advanced regions.

The second mode is the industrial development. The development of regional pillar industries based on breeding and farming is an important way to boost poverty alleviation.

The third is the mode of counterpart assistance. The main body of the model is the local government and nongovernmental organizations, and the recipients are the rural poor. There are many ways of the mode, including intelligence support, financial support, personnel training, economic cooperation, etc.

The fourth is the mode of tourism poverty alleviation. On the basis of rich tourism resources in poor and backward areas, the poverty alleviation model for poor people to get rich and achieve a well-off goal is achieved through the linkage of tourism.

The fifth model is the ecological construction. While developing the economy in the impoverished areas, we should pay attention to ecological construction and promote economic development with ecological construction, so as to achieve a virtuous circle of population, food and ecology.

Six is the migration model. By relocating resettlement households, we can improve the basic living and production conditions of the poor, and optimize the allocation of population and land resources.

\section{Analysis on the current situation of poverty alleviation in rural vocational education in China}

At present, only a small number of vocational schools in China have implemented the policy of enrollment for poor families. Some government departments and schools have formulated relevant policies, or have expressed relevant contents in the documents, but have not implemented concretely. Some schools say there is no special rule for admissions policy oriented to poor families, and some hold that differentiated enrollment policy is easy to question the fairness of enrollment. After analysis, the most fundamental reason may be that under the background of the lack of assessment system, the school is more inclined to recruit students with excellent results from their own development interests, rather than to consider the family poverty background of them.

\section{PROBLEMS Remain in RuRAL Vocational EducAtion}

\section{A. The backwardness of Anti-poverty concept, the displacement of Anti-poverty function}

Some Anti-poverty organizations often take the natural condition as the cause of backwardness, and ignore the root cause. They can never know that the backwardness of concept is actually the main obstacle of Anti-poverty project, and which mainly hinders the development of vocational education. Some related government organizations do not take the time consuming educational Anti-poverty mode as their priority in anti-poverty project, they emphasize on compulsory education and rarely concern about vocational education and barely know the function of the role vocational education plays in antipoverty project, even though they get down to anti-poverty project. According to the statistics of 2016, 3.98 million people remain as redundant laborers who cannot go to higher education in poor villages and among which 3.52 million people haven't taken part in vocational education training. Therefore, 1 million "poor and uneducated people" are added every year. Thus, we should deeply understand that the key of getting rid of poverty is to improve the quality of the new rural laborers, so, giving them vocational education, improving their quality and skills is the key to employment stabilization and income increase. Therefore, substantial implementation of vocational education can improve the creativity of new laborers, stop the transfer of poverty from generation to generation, and forbid the poverty situation to happen again. According to the statistics of development of nationwide education, some of the educational criteria such as academic diplomas of educators, area and instrument of laboratory, collection of book in library and gymnasium device are all lower than the government standard[3].

\section{B. The institutional mechanism is not sound enough, and the poverty alleviation work is invalid.}

Another important cause hinders the improvement of antipoverty is that the system is not sound enough. At present, some responsibility risk of anti-poverty is brought by indistinct of system, and lacking of efficient supervision mechanism leads to the perfunctory attitude of anti-poverty organizations. For example, even though government organizations encourage the preferential policy of enrollment of poverty areas and family, they haven't set related supervisee and assessing system, which leads to the phenomenon that many vocational villages prefer students with better scores to the students from poor family. At the present, the lack of overall planning still exists in vocational education. There is still no balance between government, vocational colleges and the market. The quality of the decision-making and management need improvement, and the support of powerful system are absent, which leads to the problem such as the depression and small scale of vocational. Thus, vocational education does not play its role in antipoverty and quality improvement of laborers. Otherwise, the enrollment of vocational colleges is out of order and the cutthroat competition exists because of the unfulfilment of some vocational education organizations. Some problems of vocational colleges demand prompt solution in anti-poverty project such as: the repeating major setting, sameness of development mode, the decline in teaching quality, weak employment and career developing ability of students.

\section{The lack of educational funds and poor educational conditions}

Actually, the cost of vocational education is higher than that of ordinary education, so more funds are needed in vocational education. At the present, the whole nation has invested more in vocational education, but the fund is still short. In Some province of the central area, according to the <middle vocational college setting criteria $>$, no vocational college of this province has meet the five criteria of floor space, the 
covered area of school, the total number of books and the number of professional teachers, prepared number of equipment. Moreover, there is no special fund for vocational education in many sections, and the additional fund has not been put into practice. The criteria of the communal fund of each student have not been set for vocational education in some provinces which further hinders the development of the rural vocational education. Furthermore, there is huge difference of the fund of each student between provinces, and according to the latest statistics, the highest criterion of Beijing(5155yuan) is 25 times more than that of Hubei province(204yuan) [4]. The lack of fund for vocational education badly restricts the development of rural vocational education, which leads to the vicious poverty circle of "low fund investment-low employment-low income-low human capital investment”.

\section{Weak faculty in middle vocational college, low number of "double-professionally-titled teachers"}

The training mode of students in some middle vocational college is purely teaching knowledge which cannot meet the criteria of being a teacher and the teaching process is lack of enjoyment.; According to the statistics of some province of the central area, the proportion of teachers and students in technical secondary school is 1 to 30 , and that of the vocational high school is 1 to 26. But the requirement of the Ministry of Education is 1to 16, which means that 20 thousand more teachers are needed in vocational schools of this province, among which the "double-professionally-titled teachers" are badly needed. Due to the hard life in the remote rural area, students graduate from colleges and technical secondary schools are not willing to work in remote countryside, which leads to weak faculty in rural vocational schools. Meanwhile, the improvement of teaching quality is really hindered by some teachers in rural vocational schools as they have old and single knowledge structure and old-fashioned teaching methods. Moreover, old and single training mode is really hard to nurture "double-professionally-titled teachers".

\section{Suggestions ON THE DEVELOPMENT OF RuRAL VOCATIONAL EDUCATION}

\section{A. Changing the concept of development and strengthening the work of helping the poor in Vocational Education}

Fully understanding the important position of Vocational Education in the work of poverty eradication needs to unify the thought and improve the understanding, and take the vocational education as a strategic measure to get rid of poverty accurately. Governments at all levels should go out of a new way to help the poor in vocational education through policy guidance, fund tilt and system innovation, and help a group of children with difficulties in vocational education and master a technology to achieve poverty and prosperity. Therefore, in the work of poverty alleviation, we must firmly establish the advanced educational concept of "Cure the poor first and treat the fool". The quality of workers must be crossed, and vocational education must first cross." And only by doing well in vocational education can we cultivate a new generation of rural laborers in order to put an end to the vicious circle of poor people getting rid of poverty and returning to poverty.

\section{B. Perfecting system construction and coordinating vocational education development plan}

Fully understanding the leading position of Vocational Education in the work of poverty alleviation, integrating the vocational education plan into the overall planning of the local economic and social development, not only takes the development of vocational education as the goal of promoting the development of the local economy and society, but also takes it as an important force to support the development of the economy and society. All localities should take the activities of creating "rural vocational education and adult education demonstration counties" as the starting point, and comprehensively promote the reform and development of rural vocational education. Improving the ability and level of Vocational Education Serving New Countryside and building new countryside. Through short-term training, we can improve the professional ability and quality of rural laborers. According to the statistics of the Ministry of education, in 2016, under the impetus of government and industry enterprises, 90 million people were trained and laid off workers, 35 million people were trained in rural labor transfer, and 46 million people were trained in rural practical technology [5].

\section{Increase investment in funds to help poor farmers geton the horse}

Government organizations at all levels should increase the investment of funds and promote the development of vocational education. In particular, it is necessary to accelerate the realization of the goal of "at least a secondary vocational school for every local level city in the poverty-stricken areas to meet the needs of local development", to promote the regional development of vocational education, to expand the function of the county-level vocational education center and to carry out the poverty alleviation. Work creates favorable conditions. The government should integrate the development of vocational education into the planning of eliminating poverty and building a new socialist countryside, and increase financial support. The concept of government led, civil society organizations, public and private vocational schools, private vocational and technical schools, the government should be supported in policies and taxes, and so that private vocational and technical schools can develop healthily. At the same time, non-governmental organizations and individuals should be encouraged to help vocational education in poor counties.

\section{Do a good job in the construction of teaching staff and strive to train "double qualified" teachers}

Vocational schools should actively carry out teaching mode reform and innovative talents training mode, enhance social service ability, vigorously support the development of poverty alleviation work, and play the advantage and role of Vocational Education in the hard work of poverty alleviation. The development of vocational schools must have a group of outstanding teachers to play a vanguard role. We must pay close attention to the construction of school infrastructure and the construction of teachers, and strive to make greater breakthroughs in a short period of time. We should take a combination of training and introduction, and employ a high level of public basic class teachers, enterprise management 
personnel, engineering technicians and skilled craftsmen to serve as part-time teachers, and focus on training a group of professional and "Double Teachers", and strive to create a high quality professional teaching teams.

\section{E. Strengthening management and the cooperation between school and enterprise}

At present, the competition of students in vocational schools is very fierce. The confusion of enrollment and the deviation of students' parents have caused the shortage of secondary vocational and technical schools and poor quality of students. Schools should actively carry out teaching reform through strict and pragmatic management, combined with the reality of local economic and social development and the characteristics of the school itself. Promote the cooperation between school and enterprise, encourage local enterprises to participate in the training of talents, change the traditional teaching mode, adopt flexible learning system and learning methods, and create conditions for students of different learning level, half work and half readers and alternation of working and learning. As long as the goal of "good management, teaching, law, entrance and employment" will be recognized and affirmed by the society, it will change the situation of the school to seek the source of the students to the students' parents to find the relationship and to go to the vocational school on the back door.

\section{CONCLUSION}

Although significant achievements have been achieved in the early poverty alleviation work, it is necessary to strengthen the vocational education and training for rural laborers in order to stabilize the early achievements and eliminate the poverty after the poverty reduction. Carrying out propaganda activities through various forms and channels will enable farmers to understand that science and technology are the primary productive forces. Improving the cultural quality of farmers, making every worker master a technology and carrying out practical technical training is a powerful way to solve the overall poverty of the region and develop the rural vocational education.

\section{REFERENCES}

[1] http://www.stats.gov.cn/tjsj/pcsj/rkpc/6rp/indexch.htm

[2] Zhu Aiguo. The strategy of poverty alleviation in Vocational Education Based on the precise perspective. [J]. new curriculum research, 2016 (01):169.

[3] Yuan Guilin, etc. Research on indicators of China's rural education development [M]. Economic Science Press, 2009:326.

[4] You Minglun, Hou Chang lin. Vocational education poverty alleviation mechanism: design framework and development ideas [J]. Vocational Education Forum, 2013 (30): 117.

[5] Shanghai Institute of Educational Sciences, Mike Research Institute, 2016 annual report on quality of Higher Vocational Education in China [M]. Beijing: Higher Education Press, 2016:50 